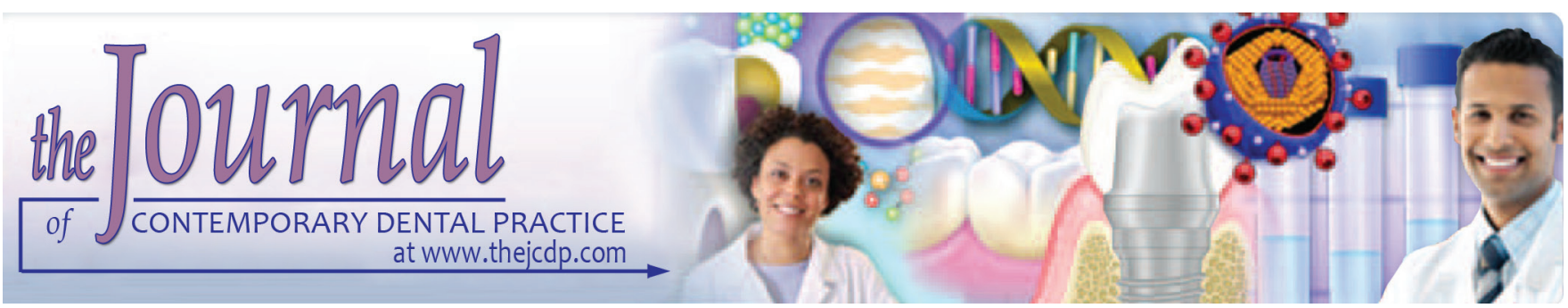

\title{
Incidence of Prosthetic Complications associated with Implant-borne Prosthesis in a Sleep Disorder Center
}

\author{
${ }^{1}$ Venkatesh B Suneel, ${ }^{2}$ Santhosh Kotian, ${ }^{3}$ Ravikanth H Jujare, ${ }^{4}$ Adarsh K Shetty, ${ }^{5}$ Sneh Nidhi, ${ }^{6}$ Shehkar Grover
}

\begin{abstract}
Background: Obstructive sleep apnea (OSA) is one of the common prevalent conditions present worldwide. The process of abnormal habits related to clenching and grinding of teeth is referred to as bruxism and is characterized under the heading of parafunctional activity of the masticatory system. Osseointegrated dental implants represent advancements in the field of odontology. Despite its high success rate, failure and complications are often associated with dental implant treatment due to a number of factors. Hence, we aimed for the present study to assess the incidence of prosthetic complications in patients rehabilitated with implant-borne prosthesis in a sleep disorder unit.
\end{abstract}

Materials and methods: The present study included the assessment of all the patients who underwent prosthetic rehabilitation by dental implants. An experienced registered prosthodontist was given duty for examination of all the cases from the record file data. Prosthetic complications in the patients were identified using photographs, radiographs, and all other relevant data of the patients obtained from the record files. All types of complications and other factors were recorded separately and analyzed.

Results: While correlating the prosthetic complications in OSA patients grouped based on number of dental implants, nonsignificant results were obtained. Significant correlation was observed while comparing the prosthetic complications

\footnotetext{
${ }^{1}$ Department of Prosthodontics including Crown \& Bridge Maharaj Ganga Singh Dental College \& Research Centre, Sri Ganganagar, Rajasthan, India

${ }^{2,3}$ Department of Prosthodontics, Faculty of Dentistry, MAHSA University, Kuala Lumpur, Malaysia

${ }^{4}$ Department of Prosthodontics, Yogita Dental College and Hospital, Khed, Maharashtra, India

${ }^{5}$ Department of Periodontics, ITS Dental College, Hospital \& Research Centre, Greater Noida, Uttar Pradesh, India

${ }^{6}$ Department of Public Health Dentistry, Maulana Azad Institute of Dental Sciences, New Delhi, India

Corresponding Author: Shehkar Grover, Department of Public Health Dentistry, Maulana Azad Institute of Dental Sciences, New Delhi, India, Phone: +918109838589 e-mail: shhekhargrover@ gmail.com
}

divided based on type of prosthesis. Fracture of the porcelain was observed in four and eight cases respectively, of screwed and cemented dental implant cases.

Conclusion: Some amount of significant correlation existed between the incidences of prosthetic complications and OSA.

Clinical significance: Proper history of the patients undergoing dental implant procedures should be taken to avoid failure.

Keywords: Dental, Implant, Obstructive sleep apnea.

How to cite this article: Suneel VB, Kotian S, Jujare RH, ShettyAK, Nidhi S, Grover S. Incidence of Prosthetic Complications associated with Implant-borne Prosthesis in a Sleep Disorder Center. J Contemp Dent Pract 2017;18(9):821-825.

Source of Support: Nil

Conflict of Interest: None

\section{INTRODUCTION}

One of the highly prevalent conditions affecting a significant number of males and females worldwide is obstructive sleep apnea (OSA). Strong correlation of OSA with epidemic obesity has also been suggested. The preliminary clinical manifestation of this disease is recurrent episodes of obstruction of upper airway track. ${ }^{1}$ This further leads to reduction in the ventilation process resulting in recurrent arousals and episodic oxyhemoglobin desaturations during sleep time. Daytime hypersomnolence along with other major clinical adverse effects is commonly found to be associated with this condition. ${ }^{2}$ Association of sleep bruxism and high clench index has been reported in patients suffering from OSA. ${ }^{3}$

Bruxism refers to the process of abnormal habit related to clenching and grinding of teeth, and is characterized under the heading of parafunctional activity of the masticatory system. ${ }^{4} \mathrm{~A}$ wide spectrum of factors are hypothesized to be the causative agent for the occurrence of bruxism. Some cases of bruxism might show no major effect on the oral and perioral tissues, while some 
cases can show serious problems including temporomandibular disorder, tooth mobility, headache, toothache, and problems associated with various prosthetic restorations. ${ }^{5}$

Advancements in the field of odontology can be highlighted in terms of osseointegrated dental implants. Despite its high success rate, failure and complications are often associated with dental implant treatment due to a number of factors. Bruxism is also said to have some amount of effect on the success of implant-supported prosthesis. ${ }^{6}$ Hence, we aimed for the present study to assess the incidence of prosthetic complications in patients rehabilitated with implant-borne prosthesis in a sleep disorder unit.

\section{MATERIALS AND METHODS}

The present study was conducted in the Department of Oral Implantology, and included assessment of all the patients who underwent prosthetic rehabilitation by dental implants from June 2013 to July 2016. Ethical approval was taken from the institutional ethical committee, and written consent was obtained after explaining in detail the entire research protocol. STrengthening the Reporting of OBservational studies in Epidemiology guidelines were used for planning and conducting the present study. In the dental institution, retrospective collection of all the data records was done from the patient's records of the selected patients from the sleep disorder unit of the institution. Inclusion criteria for the present study included:

- Patients diagnosed with OSA

- Patients rehabilitated with implant-borne prosthesis

- Patients belonging to the age group of 25 to 50 years Exclusion criteria for the present study included:

- Patients with history of any known drug allergy

- Patients having history of any other systemic illness

- Patients who have undergone any other major surgical procedure in the past 1 year

For achieving unbiased randomization, an experienced registered prosthodontist was given duty for examination of all the cases from the record file data. The prosthodontist was unaware of the result obtained after the sleep analysis of the included patients. Prosthetic complications in the patients were identified using the photographs, radiographs, and all other relevant data of the patients obtained from the record files. Occurrence of following factors was included under the category of prosthetic complications:

- Abutment tooth fracture

- Fracture of the connector component

- Fracture or loosening of the screw

- Fracture of the abutment

- Ceramic chipping

- Prosthesis and implant fracture
All the type of complications and other factors were recorded separately. Criteria given by the Spanish Respiratory Association were used for the identification of OSA in various participants. ${ }^{7}$

\section{Statistical Analysis}

All the results were analyzed by Statistical Package for the Social Sciences software 16.0. Chi-squared test, one-way analysis of variance, and multivariate regression curve analysis were used for the assessment of the level of significance. The $\mathrm{p}<0.05$ was considered statistically significant.

\section{RESULTS}

Details of the patients with and without prosthetic complications are highlighted in Table 1 and Graph 1. Nonsignificant results were obtained while correlating the prosthetic complications in OSA patients grouped based on number of dental implants. Based on the type of fixation of dental implants, two types were found: Cemented and screwed. Prosthetic complications were present in 19 and 12 cases of cemented and screw type of dental implants respectively. A significant correlation was observed while comparing the prosthetic complications divided based on the type of prosthesis $(p<0.05)$. Table 2 and Graph 2 show the incidences of various types of complications. Loosening of the screw was observed in four cases, while fracture of the dental implant was observed in three cemented cases of dental implants. Fracture of the porcelain was observed in four and eight cases respectively, of screwed and cemented dental implant cases.

\section{DISCUSSION}

The OSA is one of the common prevalent conditions affecting approximately $6 \%$ of the world's middle-aged population with an apnea-hypopnea index (AHI) of

Table 1: Details of the patients with or without prosthetic complications

\begin{tabular}{llll}
\hline & \multicolumn{2}{l}{ Prosthetic complication } & \\
\cline { 2 - 3 } Parameter & Present & Absent & p-value \\
\hline Quantity of dental implants & 4 & 3 & 0.25 \\
Number of units & 5 & 2 & $0.02^{*}$ \\
$\begin{array}{l}\text { Fixation type } \\
\quad \text { Cemented }\end{array}$ & 19 & 42 & 0.36 \\
$\quad$ Screwed & 12 & 21 & \\
$\begin{array}{l}\text { Prosthesis type } \\
\text { SC }\end{array}$ & & & \\
$\quad$ Complete prosthesis & 2 & 29 & $0.03^{*}$ \\
$\quad$ Partial prosthesis & 21 & 3 & \\
\hline *Significant & & 31 & \\
\end{tabular}




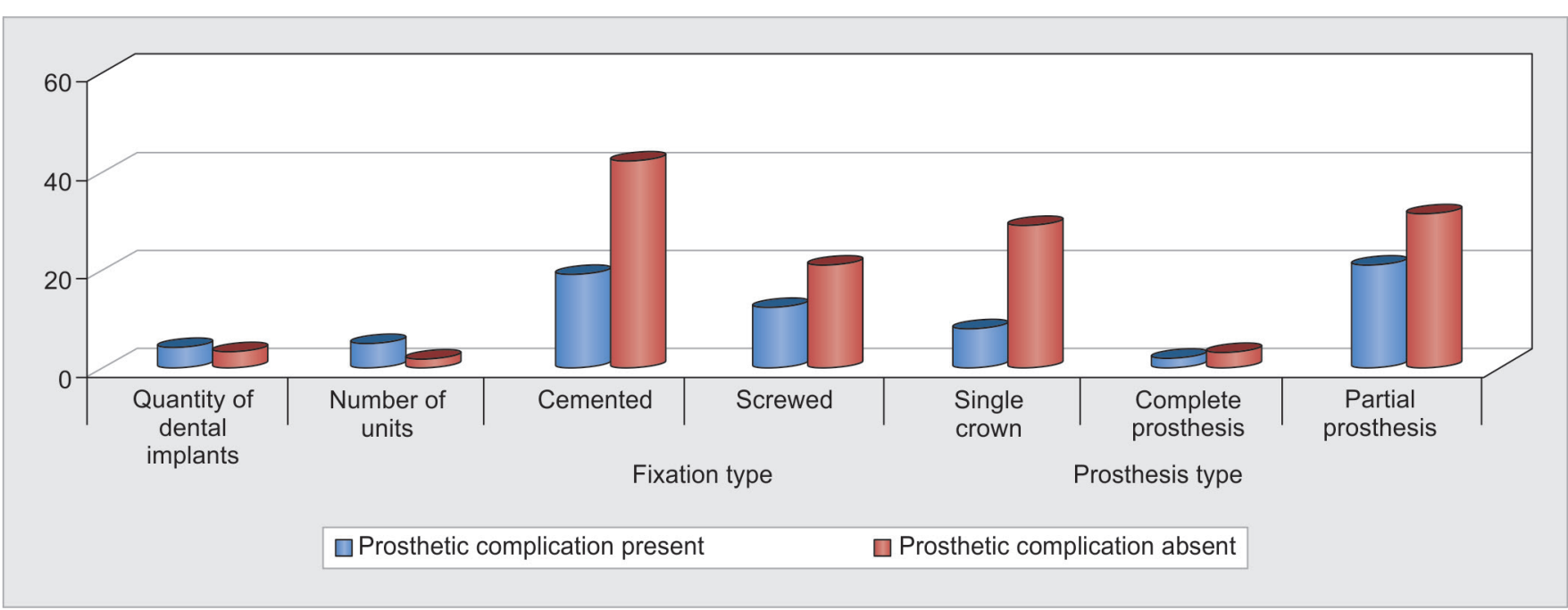

Graph 1: Subtle elements of the patients with or without prosthetic complications

Table 2: Incidence of occurrence of various types of complications

\begin{tabular}{|c|c|c|c|c|c|}
\hline \multirow[b]{2}{*}{ Complication } & \multicolumn{2}{|c|}{ Type of fixation } & \multicolumn{3}{|c|}{ Type of prosthesis } \\
\hline & Screwed & Cemented & Single crown & $\begin{array}{l}\text { Complete } \\
\text { prosthesis }\end{array}$ & $\begin{array}{l}\text { Partial } \\
\text { prosthesis }\end{array}$ \\
\hline Loosening of screw & 4 & 2 & 2 & 0 & 3 \\
\hline Fracture of dental implant & 0 & 3 & 2 & 0 & 2 \\
\hline Fracture of porcelain & 4 & 8 & 1 & 1 & 10 \\
\hline Fracture of screw & 2 & 2 & 1 & 1 & 3 \\
\hline Decementation & 2 & 4 & 2 & 0 & 3 \\
\hline Total complications & 12 & 19 & 8 & 2 & 21 \\
\hline
\end{tabular}

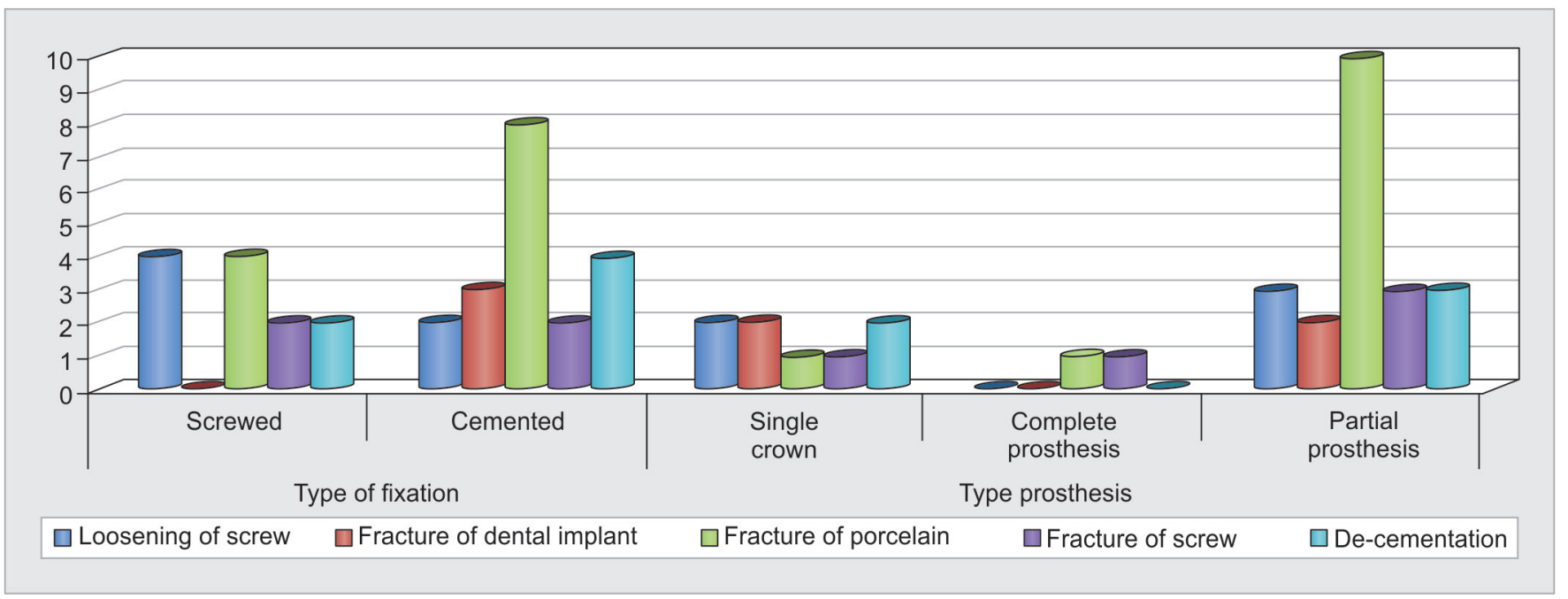

Graph 2: Rate of event of different types of complexities

more than 5. The value is even higher in the elderly population and in patients with various metabolic and systemic diseases. ${ }^{8}$ Clinical manifestation of OSA includes recurrent airway obstruction that lasts longer than 10 seconds during the time period of sleep. Stereotypical rhythmic movement of masticatory muscles characterizes bruxism, resulting in grindings of teeth. Stress and sleep disorders further exaggerate these manifestations. ${ }^{9}$ Results of various studies show that a positive correlation exists between the bruxism during OSA and tooth grinding. ${ }^{10}$ Hence, we aimed for the present study to assess the incidences of prosthetic complications in patients rehabilitated with implant-borne prosthesis in a sleep disorder unit.

In the present study, we observed that approximately $80 \%$ of the complications of prosthesis occurred in patients presenting with OSA (Table 1 and Graph 1). The highest AHI was present in the patients having screw fractures 
(Table 2 and Graph 2). Our results were in correlation with the results obtained by Anitua et al, ${ }^{11}$ who reported nearly similar findings. Anitua et $\mathrm{al}^{11}$ assessed the prosthetic complications associated with OSA in patients who underwent prosthetic rehabilitation by dental implants. Out of 172 patients included in their retrospective study, implant-supported prosthesis was present in 67 patients. In 22 prosthesis cases, 30 complications were identified by the authors in 16 different patients. In 14 cases, porcelain fracture was present, whereas screw or implant fracture was present in eight cases. They also observed screw loosening and decementation in three and five cases respectively. About 117 months was the mean follow-up time after the prosthesis placement. From the results, they concluded that higher prosthetic complications are associated with OSA. Wittneben et $\mathrm{al}^{12}$ assessed the complication rates retrospectively associated with implant-supported fixed dental prostheses and single crowns (SCs). They comprehensively examined the complete medico-dental history along with their clinical and radiographic details of the patients included in the present study. They observed that a total of 397 reconstructions were done in 303 participants. A failure rate of $4.5 \%$ was observed in the approximately 10 -year follow-up time. Ceramic chipping was the most commonly encountered complication followed by occlusal screw loosening and loss of retention. However, they did not observe any occlusal fracture cases in their study. A complication rate of approximately $25 \%$ was observed in their study. From the results, they concluded that the most frequently involved complication associated with prosthesis is ceramic chipping.

Mangano et $\mathrm{al}^{13}$ conducted a retrospective study to assess the failure rate and complication rates of dental implant-associated fixed restorations supported by locking-taper implants. They analyzed a total of 1,494 implants, which were placed in 642 patients over a 10-year time period. They observed that 12 maxillary and 7 mandible implants failed in total. Lack of osseointegration and peri-implantitis were the main reasons found to be responsible for the failure of dental implants. Dental implant survival rate of approximately 99\% was observed in their study. No significant correlation was observed between the dental implant failure rate and position, location, or other clinical parameters of dental implants. From the results, they concluded that for the rehabilitation of partial or completely edentulous dental arches, locking-taper implants appear to be a successful procedure.

Chrcanovic et $\mathrm{al}^{14}$ investigated the correlation between the bruxism and risk associated with failure of dental implants. In their retrospective study, they analyzed over 2,500 patients, who were rehabilitated with over
10,000 dental implants in a single specialty dental clinic. They collected all the data on the dental implant and patients receiving those implants. For approximately 3,500 dental implant cases, complete information was available regarding placement of dental implants. These implants were placed in approximately 1,000 patients. The total number of dental implants that failed was 174, giving a failure rate of $13 \%$ for bruxers and $4.6 \%$ for nonbruxers. The results were found to be statistically significant. Their statistical model showed a significant correlation between bruxism and risk of failure of dental implants. From the results, they concluded that increased risk of dental implant failure is associated with bruxism. Yadav et $\mathrm{al}^{15}$ evaluated the complications associated with dental implants in bruxers. They analyzed a total of 1,100 patients, who underwent prosthetic rehabilitation by dental implants. They observed that the maxillary anterior tooth region was the most common site of placement of dental implants. They observed a significant difference while comparing the two study groups. From the results, they concluded that bruxism significantly affects the success of dental implants.

The present study had a few limitations of having small sample size, and no separate consideration was taken for various etiologic factors of OSA in patients undergoing implant-borne prosthesis.

\section{CONCLUSION}

From the above results, the authors concluded that significant correlation existed between the incidences of prosthetic complications and OSA to some extent. However, future studies are recommended.

\section{REFERENCES}

1. Young T, Palta M, Dempsey J, Skatrud J, Weber S, Badr S. The occurrence of sleep-disordered breathing among middle-aged adults. N Engl J Med 1993 Apr;328(17):1230-1235.

2. Remmers JE, deGroot WJ, Sauerland EK, Anch AM. Pathogenesis of upper airway occlusion during sleep. J Appl Physiol Respir Environ Exerc Physiol 1978 Jun;44(6):931-938.

3. Esposito M, Grusovin MG, Coulthard P, Thomsen P, Worthington HV. A 5-year follow-up comparative analysis of the efficacy of various osseointegrated dental implant systems: a systematic review of randomized controlled clinical trials. Int J Oral Maxillofac Implants 2005 Jul-Aug;20(4):557-568.

4. Jernt $\mathrm{T}$, Lindén B, Lekholm U. Failures and complications in 127 consecutively placed fixed partial prostheses supported by Brånemark implants: from prosthetic treatment to first annual check-up. Int J Oral Maxillofac Implants 1992 Spring;7(1):40-44.

5. Misch CE. The effect of bruxism on treatment planning for dental implants. Dent Today 2002 Sep;21(9):76-81.

6. Lobbezoo F, Brouwers JE, Cune MS, Naeije M. Dental implants in patients with bruxing habits. J Oral Rehabil 2006 Feb;33(2):152-159. 
7. Duran-Cantolla J, Puertas-Cuesta FJ, Pin-Arboledas G, MariaCano JS. Consensus national paper on sleep apnea hypopnea syndrome. Arch Bronconeumol 2005;41:1-110.

8. Ding N, Ni BQ, Zhang XL, Huang HP, Su M, Zhang SJ, Wang H. Prevalence and risk factors of sleep disordered breathing in patients with rheumatic valvular heart disease. J Clin Sleep Med 2013 Aug;9(8):781-787.

9. Monahan K, Redline S. Role of obstructive sleep apnea in cardiovascular disease. Curr Opin Cardiol 2011 Nov;26(6):541-547.

10. Punjabi NM, Caffo BS, Goodwin JL, Gottlieb DJ, Newman AB, O'Connor GT, Rapoport DM, Redline S, Resnick HE, Robbins JA, et al. Sleep-disordered breathing and mortality: a prospective cohort study. PLoS Med 2009 Aug;6(8):e1000132.

11. Anitua E, Saracho J, Almeida GZ, Duran-Cantolla J, Alkhraisat MH. Frequency of prosthetic complications related to implant-borne prosthesis in a sleep disorder unit. J Oral Implantol 2017 Feb;43(1):19-23.
12. Wittneben JG, Buser D, Salvi GE, Bürgin W, HicklinS, BräggerU. Complication and failure rates with implant-supported fixed dental prostheses and single crowns: a 10-year retrospective study. Clin Implant Dent Relat Res 2014 Jun;16(3):356-364.

13. Mangano F, Macchi A, Caprioglio A, Sammons RL, Piattelli A, Mangano C. Survival and complication rates of fixed restorations supported by locking-taper implants: a prospective study with 1 to 10 years of follow-up. J Prosthodont 2014 Aug;23(6):434-444.

14. Chrcanovic BR, Kisch J, Albrektsson T, Wennerberg A. Bruxism and dental implant failures: a multilevel mixed effects parametric survival analysis approach. J Oral Rehabil 2016 Nov;43(11):813-823.

15. Yadav K, Nagpal A, Agarwal SK, Kochhar A. Intricate assessment and evaluation of effect of bruxism on long-term survival and failure of dental implants: a comparative study. J Contemp Dent Pract 2016 Aug;17(8):670-674. 